\title{
A.JO'「E
}

African Journal of Teacher Education

ISSN 1916-7822. A Journal of Spread Corporation

Volume 10. No. 12021 Pages 307-324

\section{The Effects of a School-Based Physical Activity Teacher Intervention on the Physical Activity Attitudes and Practices of Adolescent Students in Lagos, Nigeria}

\author{
Olalekan Remigious Osifeko ${ }^{1}$, Rowena Naidoo $^{1}$, \& Verusia Chetty ${ }^{2}$ \\ College of Health Sciences, University of KwaZulu-Natal, \\ Durban, South Africa
}

\begin{abstract}
Background: Nigerian adolescents are faced with challenges around physical inactivity. Poor attitudes to, and practices in, physical activity during school physical education (PE) classes are also a challenge. Our study integrated an innovative PE teaching methodology (autonomous support style) into a professional development training (PDT) programme for teachers to promote PA among adolescents. The study aimed at determining the effects of this school-based physical activity intervention for teachers on the physical activity attitudes and practices of adolescents. This study employed a descriptive quantitative research approach to determine the attitudes and practices of adolescents. One thousand two hundred students were recruited from twenty-four junior secondary schoolsthrough an intact group design process. A PE teacher from each school was included in the PDT intervention programme. The main components of the intervention included training PE teachers to influence their students' attitudes and practices through the use of an autonomous support style of teaching.PE teachers allocated to the intervention group implemented the autonomous support style of teaching at the schools in the intervention group for four months. There was a pre-intervention baseline assessment of the students' physical activity attitudes and practices, with a second assessment following the intervention. Results showed that there were significant $(p<0.05)$ changes, post-intervention, in the adolescents' attitudes to, and practices in, physical activity participation during PE classes, and at lunch or break-time during the school day.
\end{abstract}

Keywords: physical activity; attitudes; practice; school-based; intervention; professional development training (PDT).

${ }^{1} \mathrm{PhD}$ in Sports Science (lekanfeko5@gmail.com) specializes in Biokinetics, Exercise and Leisure Sciences ${ }^{1} \mathrm{PhD}$ in Sports Science (naidoor3@ukzn.ac.za) specializes in Biokinetics, Exercise and Leisure Sciences ${ }^{2} \mathrm{PhD}$ in Health Sciences (chettyve@ukzn.ac.za) specializes in Physiotherapy 


\section{Introduction}

Physical activity (PA) has important health benefits during adolescence (World Health Report 2013). Regular physical activity reduces the risk of sedentary behaviour, possibly obesity and cardiovascular disease among adolescents (Andersen et al., 2011). Furthermore, regular physical activity during adolescence influences mental and emotional health, as well as physical well-being (Biddle et al., 2011; Singh et al., 2012). Inadequate leisure time, inactivity, obesity and chronic health issues plague the lives of millions of adolescents globally (CDFHS, 2013). Although the benefits of physical activity are well documented, the participation of adolescents in physical activity has drastically declined globally, with many adolescents adopting sedentary lifestyles (Hallal et al., 2012). Moreover, the widespread inactivity among adolescents has been steadily increasing over the past few decades, and the harmful effects of this are reflected in the documentation of global health profiles (Lonsdale et al., 2016). In Nigeria, studies have also revealed that adolescents are not participating enough in physical activity (Adeniyi, et al., 2011; Akinroye et al., 2014; Mojisola and Oladimeji, 2017).

A school-based physical activity intervention could offer a platform for adolescents to participate more in beneficial PA. However, adolescents are physically inactive at school; and even during physical education (PE) classes, where physical activity is encouraged. In many schools, adolescents are still not participating enough (Deidre, 2016). A Nigerian study evidenced that the proportion of time spent doing physical activity in PE classes is low (35.5\%), and this has consequently contributed to the students' negative attitudes to, and practices in, physical activity (Akinroye et al., 2014). Another study in Nigeria also highlighted that, despite certified PE teachers in Nigeria's education system, and the school structures acknowledging the health benefits of physical activity, Nigerian students' attitudes and practices are unlikely to lead to any health-related benefits (Akinroye et al., 2014). Some of the reason's researchers have given for the poor uptake of physical activity by adolescents in Nigeria include poor programme guidelines informing the roll-out of physical activity in schools, poor teaching methodologies adopted by teachers, and poor resources, such as a lack of facilities and equipment for physical activity (Adebayo, 2015). Schools are further challenged by systemic issues where PE is not prioritised and academic subjects are given precedence (Adeniyi et al., 2016). Researchers in previous studies have concluded that these factors negatively influence the attitude and practices of adolescents with regard to the uptake of physical activity (Physical Activity Guidelines Advisory Committee Report, 2008; Mojisola et al., 2017). Previous Nigerian studies have proposed the development and implementation of professional development training (PDT) programmes to mitigate some of these issues which are dissuading students from participating in physical activity in schools (Ajoku, 2013). 
Growing evidence suggests that a PDT programme will enhance the teaching and learning platform in schools and could improve the attitudes and practices of adolescents regarding physical activity (Guskey, 2003; Adewale et al., 2016; Aubert et al., 2018) by offering appropriate and innovative approaches that are globally relevant (Adeniyi et al., 2016; Mojisola \& Oladimeji, 2017). In this paper, the authors have developed a PDT programme through consultation with Nigerian PE teachers. The PDT programme included teacher-training workshops for PE teachers. The workshops introduced and integrated a new autonomous support style of teaching to promote physical activity. This paper aimed to determine the effects of a school-based physical activity PDT programme on the attitudes and practices of adolescents regarding physical activity in Lagos, Nigeria.

\section{Methods}

A descriptive quantitative research study was conducted to determine the attitudes and practices of adolescents regarding school-based physical activity, following a PDT intervention. The PDT intervention focused on PE teachers' knowledge of physical activity teaching methods during PE classes, as well as the application of novel methodologies to promote physical activity in schools. Creswell (2014) established that the method of data collection is essentially determined by the problem statement of the study and the research questions posed. In addition, Martin et al. (2015) explained that data, if it is to be generalised, should be structured using the scientific methods of a quantitative approach to investigate an identified problem, in order to determine the effect of a study or intervention on specific groups of people. Therefore, based on the problem and the related literature, the researcher chose the quantitative research approach to address physical activity attitudes and participation in junior secondary schools, following a PDT intervention for the PE teachers.

\section{Study setting}

The study was conducted in an urban area of Lagos State in Nigeria. The intact group method (this is an already-formed group of people in an organisation, such as classrooms of students in schools, political organisations and church groups) was utilised (Belton \& MacDonncha, 2010). No selection procedure was used: all the schools in the Epe Local Government Area (LGA), Lagos State were included. All junior secondary schools in each of the Epe Local Council Development Areas (LCDAs) were selected. Six schools from Epe-central LCDA; eight schools from Agbowa-ikosi LCDA; and ten schools from Eredo LCDA were included, resulting in 24 junior secondary schools (JSS) participating in the study.

\section{Sample and sampling procedures}

The schools were assigned to either an experimental group or a control group in their various LCDAs, through the process of intact group design (based on the distance between the schools, the groups were in 
the same LCDA area to allow mutual communication during the implementation, when the need arose). The experimental group included the students and PE teachers who participated in the PDT. A purposive sample of students $(n=1,200)$ in junior secondary schools (JSS) was selected. The sample comprised 24 schools (14 intervention and 10 control); and of the 1,200 adolescents, 700 students were included in the intervention group and 500 students in the control group.

\section{Procedures}

The lead researcher visited each school and explained the purpose of the study, which was further clarified in the information and consent forms. The schools were then separated into intervention and control groups. The PE teachers in the intervention schools participated in the PDT intervention programme to upgrade their physical activity teaching methodology. The PDT programme on physical activity teaching methodologies was used to train teachers to promote physical activity among the students. The control group teachers continued with their normal teaching methods.

\section{The intervention}

The PDT intervention programme used a workshop approach to train PE teachers on physical activity teaching methods, including using an autonomous support style of teaching to improve the uptake of physical activity by students. The workshop training sessions introduced an autonomous support style of teaching as the teaching methodology (Hagger et al., 2013; Yew et al., 2013). It also offered advice on structuring the PE classes in motivationally adaptive ways and encouraged the involvement of the students by striving to satisfy their basic psychological needs (providing opportunities for choice and input; empathising with the students' perspectives; demonstrating and/or establishing peer-learning groups; supporting co-operation) (Lonsdale et al., 2016; The Community Guide, 2013). The intervention content covered physical activity teaching methodology to promote student physical activity during PE classes. The programme provided improved teaching approaches for the teaching of the existing PE syllabus content, in order to improve adolescents' attitudes and practices regarding physical activity. It also aimed to promote a learning environment conducive to (potentially) enhancing the students' health outcomes (Kahar et al., 2018; Cheon et al., 2015). It sought to develop a deeper understanding of the different strategies and methods used in teaching (James et al., 2011). The intervention also aimed to establish a proper understanding of the determinants of attitudes and practices regarding physical activity, before incorporating the teaching methods to promote physical activity during PE classes (Lonsdale et al., 2016).

\section{Implementing the Intervention Programme}

The PDT intervention programme addressed concerns regarding adolescents' physical inactivity at school, including during PE classes, and negative attitudes and practices towards physical activity. The PDT 
programme was designed to introduce autonomous support styles of teaching when conducting practical classes. All content was in line with the existing PE curriculum; at the same time ensuring that physical activity was prioritised to promote physical activity in the school.

An autonomous support style offers the students' opportunities to choose the activity. This served as a strategy to motivate students to increase the intensity of their physical activity from moderate to vigorous. Furthermore, taking into consideration students' input and opinions, allowed the teacher to understand and acknowledge difficulties experienced by the students within the PE class. The intervention included educating teachers on the importance of clear instructions prior to tasks or activities; delivery methods, specifically regarding demonstrating the physical activity; and the establishment of peer-learning groups, where the teacher grouped the students together to demonstrate a given task. Each member of the group was responsible for solving the task, and for helping their teammates learn what they had been taught, until all group members successfully demonstrated and completed the task. The lack of resources was a challenge in many schools; hence, the teachers were also trained on equipment improvisation and on how to adapt games/sport/activities using the available resources.

The training workshops for teachers were conducted before the beginning of the school term. The PE teachers who participated in the training workshops were divided into three separate groups, and the workshops lasted for six days. Thereafter, the intervention was implemented across two school terms for a period of four months. The PE teachers implemented the skills learnt from the professional development intervention workshops. The intervention programme was monitored for two hours, every other day each week. The teachers reflected on their skills and knowledge, newly acquired in the training workshops, and their impact on the current delivery of their PE lessons. The teachers were assisted with queries and challenges experienced. In particular, teaching and learning methods were modified and adjusted throughout the duration of the intervention. This enhanced the teachers' learning experience and at the same time promoted enjoyable physical activity among the learners.

\section{Data Collection}

Students completed the Attitude and Practice of Physical Activity Questionnaire for Adolescents (APPAQA). The questionnaire, which has been used in similar studies elsewhere in Africa, measures the adolescents' attitudes and practices and was adapted for use in this school-based physical activity intervention. The tool was developed for adolescents by the Africa Centre for Disease Control and Prevention (ACDCP) (2010). The questionnaire is in three sections: Section A accessed the demographic data. Section B assessed the attitudes to physical activity, and comprised nine questions on a Likert scale of strongly disagree, disagree, neutral, agree and strongly agree. Section $\mathrm{C}$ assessed the practices regarding 
physical activity during PE classes and physical activity at break or after school, and comprised 25 multiplechoice questions. The survey was administered pre-and post-intervention. The researcher and the research assistants administered the questionnaires, which took between 20 and 30 minutes to complete. Before the intervention a baseline assessment was conducted for all the students and a second assessment was conducted post-intervention.

\section{Statistical Analysis}

The data were analysed with descriptive and inferential statistics to test significant changes, from pre- to post-intervention. Analyses were specified, based on the student's responses on the questionnaires. These responses were grouped into demographic data; attitudes of students to physical activity; and practices of students regarding physical activity. The distributions of respondents' ages and gender were analysed. The one-sample t-test was used to test for significant agreement or disagreement to statements measuring attitudes to physical activity. The paired sample t-test explored differences in attitudes, pre- to postintervention. The Wilcoxon Signed Ranks Test was used to analyse differences in physical activity pre-to post-intervention. Lastly, analysis of covariance (ANCOVA) was used to test the differences in postintervention scores between the two groups, after being corrected for by the pre-intervention scores.

\section{Ethical Considerations}

Ethical approval was obtained from the University of KwaZulu-Natal (HSS/1750/018). Permission was also obtained from the Lagos State Ministry of Education through the Permanent Secretary. Before the study commenced, informed consent forms were obtained from the study participants.

\section{Results}

Questionnaires were completed by 1200 students at the initial stage of the study. At the post-intervention stage, a total of 1193 students completed the questionnaire, representing a $99.41 \%$ retention rate in the final analysis. The demographic information of the students who participated in this study is presented in Table 1. The ages of the respondents ranged from 13 to 16 years, with the majority either 13 or 14 yearsold. There were more females than males.

Table 1: Demographic data

\begin{tabular}{lllll}
\multirow{2}{*}{ Variable } & Categories & Full sample & Intervention & Control \\
& & Frequency $(\%)$ & Frequency $(\%)$ & Frequency (\%) \\
\hline \multirow{2}{*}{ Gender } & Male & $490(41.1)$ & $288(41.4)$ & $202(40.6)$ \\
\cline { 2 - 5 } & Female & $703(58.9)$ & $407(58.6)$ & $296(59.4)$ \\
\hline & 13 years & $436(36.5)$ & $253(36.4)$ & $183(36.7)$ \\
\hline
\end{tabular}


The Effects of a School-Based Physical Activity Teacher Intervention on the Physical Activity Attitudes and Practices of Adolescent Students in Lagos, Nigeria

\begin{tabular}{lllll}
\cline { 2 - 4 } Age & 14 years & $309(25.9)$ & $176(25.3)$ & $133(26.7)$ \\
\cline { 2 - 5 } & 15 years & $288(24.1)$ & $168(24.2)$ & $120(24.1)$ \\
\cline { 2 - 5 } & 16 years & $160(13.4)$ & $98(14.1)$ & $62(12.4)$
\end{tabular}

The assessment of nine statements measuring students' attitude to physical activity participation during PE classes, both pre-intervention and post-intervention, is presented in Table 2. Of the nine items, five represent a positive attitude to physical activity and four represent a negative attitude to physical activity.

Table 2: Assessment of the students' attitudes to physical activity during the school day.

\begin{tabular}{|c|c|c|c|c|c|}
\hline \multirow[t]{2}{*}{ Item } & \multirow[t]{2}{*}{ Period } & $\begin{array}{l}\text { Intervention } \\
(n=689)\end{array}$ & \multirow[t]{2}{*}{ p-value ${ }^{1}$} & $\begin{array}{l}\text { Control } \\
(n=493)\end{array}$ & \multirow[t]{2}{*}{ p-value ${ }^{1}$} \\
\hline & & Mean (SD) & & Mean (SD) & \\
\hline \multirow{2}{*}{$\begin{array}{l}\text { 1. I would like to have } \\
\text { more time to play sport } \\
\text { or games with my } \\
\text { friends. }\end{array}$} & Pre & $2.99(0.83)$ & \multirow{2}{*}{$<.0005$} & $3.09(0.72) *$ & \multirow{2}{*}{.461} \\
\hline & Post & $4.25(0.66) *$ & & $3.13(0.76) *$ & \\
\hline \multirow{2}{*}{ 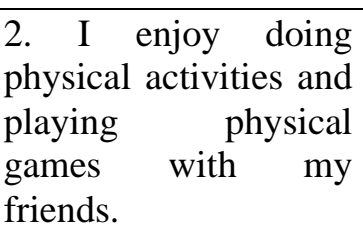 } & Pre & $3.03(0.79)$ & \multirow{2}{*}{$<.0005$} & $3.07(0.78) *$ & \multirow{2}{*}{.155} \\
\hline & Post & $4.31(0.59) *$ & & $3.14(0.82) *$ & \\
\hline \multirow{2}{*}{$\begin{array}{l}\text { 3. I find my physical } \\
\text { education } \\
\text { interesting. }\end{array}$} & Pre & $2.98(0.78)$ & \multirow{2}{*}{$<.0005$} & $2.92(0.78)^{\$}$ & \multirow{2}{*}{.781} \\
\hline & Post & $4.39(0.68) *$ & & $2.93(0.82)$ & \\
\hline \multirow{2}{*}{$\begin{array}{l}\text { 4. I am excited about } \\
\text { physical education }\end{array}$} & Pre & $3.04(0.77)$ & \multirow{2}{*}{$<.0005$} & $2.94(0.79)^{\$}$ & \multirow{2}{*}{.168} \\
\hline & Post & $4.27(0.69) *$ & & $3.01(0.77)$ & \\
\hline \multirow{2}{*}{$\begin{array}{l}\text { 5. The games and } \\
\text { physical exercises we } \\
\text { do in physical } \\
\text { education class make } \\
\text { learning fun. }\end{array}$} & Pre & $3.00(0.93)$ & \multirow{2}{*}{$<.0005$} & $2.84(0.77)^{\$}$ & \multirow[t]{2}{*}{.357} \\
\hline & Post & $4.28(0.84) *$ & & $2.89(0.81)$ & \\
\hline \multirow{2}{*}{$\begin{array}{l}\text { 6. Physical education } \\
\text { classes are boring. }\end{array}$} & Pre & $2.89(1.12)$ & \multirow{2}{*}{$<.0005$} & $2.92(1.07) *$ & \multirow{2}{*}{.780} \\
\hline & Post & $1.46(0.66)^{\$}$ & & $2.94(1.04) *$ & \\
\hline \multirow{2}{*}{$\begin{array}{l}\text { 7. I do not have fun } \\
\text { when I am doing } \\
\text { physical activity. }\end{array}$} & Pre & $2.99(1.21)$ & \multirow[t]{2}{*}{$<.0005$} & $2.77(1.190)^{\$}$ & \multirow[t]{2}{*}{.030} \\
\hline & Post & $1.37(0.59)^{\$}$ & & $2.94(1.18) *$ & \\
\hline $\begin{array}{l}\text { 8. I feel uncomfortable } \\
\text { or embarrassed in }\end{array}$ & Pre & $2.91(1.21)$ & $<.0005$ & $3.06(1.19) *$ & .853 \\
\hline
\end{tabular}




\begin{tabular}{|l|l|l|l|l|l|}
\hline $\begin{array}{l}\text { exercise clothes during } \\
\text { PE classes }\end{array}$ & Post & $1.58(0.79)^{\$}$ & & $3.08(1.18)^{*}$ & \\
\hline $\begin{array}{l}\text { 9. I see long sessions } \\
\text { of exercise during PE } \\
\text { classes as a } \\
\text { punishment }\end{array}$ & Pre & $2.64(1.21)$ & & $2.49(1.23) *$ & \multirow{2}{*}{$<050$} \\
\cline { 2 - 3 } \cline { 5 - 6 } & Post & $1.53(0.64)^{\$}$ & & $2.50(1.24) *$ & \\
\hline
\end{tabular}

$\mathrm{SD}=$ standard deviation

* indicates significant agreement at .05 level, following a one-sample t-test

$\$$ indicates significant disagreement at .05 level, following a one-sample t-test

${ }^{1}$ paired samples t-test for differences pre- to post-intervention

For the intervention group, there was significant agreement (post-intervention) with all the positively-worded items; and significant disagreement with all the negatively-worded items. In addition, there was a significant improvement in their attitude to participation in school-based physical activity, reflected in all the items. While there was some significant agreement and disagreement with specific items, both pre-and post-intervention, the control group showed a significant change in only one item - 'I do not have fun when I am doing physical activity', with which less disagreement was shown post-intervention.

After correction for the pre-intervention scores, compared to the control group, the intervention group showed significantly more agreement with the positively-worded items and significantly less disagreement with the negatively-worded items. It is evident that the intervention had a positive effect on students' attitudes towards physical activity. The results are summarised in Table 3, below.

Table 3: ANCOVA analysis of the post-intervention results

\begin{tabular}{|l|c|c|c|}
\hline \multicolumn{1}{|c|}{ Variables } & \multicolumn{2}{c|}{$\begin{array}{c}\text { Estimated mean agreement scores post- } \\
\text { intervention }\end{array}$} & \multirow{2}{*}{ p-value } \\
\cline { 1 - 2 } $\begin{array}{l}\text { Items on ATTITUDE to physical } \\
\text { activity }\end{array}$ & Intervention group & Control group & \\
\hline $\begin{array}{l}\text { 1. I would like to have more time to play } \\
\text { sport or games with my friends. }\end{array}$ & 4.25 & 3.13 & $<.0005$ \\
\hline $\begin{array}{l}\text { 2. I enjoy doing physical activities and } \\
\text { playing physical games with my friends. }\end{array}$ & 4.31 & 3.14 & $<.0005$ \\
\hline $\begin{array}{l}\text { 3. I find my physical education class } \\
\text { interesting. }\end{array}$ & 4.39 & 2.93 & $<.0005$ \\
\hline 4. I am excited about physical education. & 4.27 & 3.00 & $<.0005$ \\
\hline
\end{tabular}


The Effects of a School-Based Physical Activity Teacher Intervention on the Physical Activity Attitudes and Practices of Adolescent Students in Lagos, Nigeria

\begin{tabular}{|l|c|c|c|}
\hline $\begin{array}{l}\text { 5. The games and physical exercises we } \\
\text { do in physical education class make } \\
\text { learning fun. }\end{array}$ & 4.28 & 2.89 & $<.0005$ \\
\hline \hline 6. Physical education classes are boring. & 1.46 & 2.94 & $<.0005$ \\
\hline $\begin{array}{l}\text { 7. I do not have fun when I am doing } \\
\text { physical activity. }\end{array}$ & 1.37 & 2.94 & $<.0005$ \\
\hline $\begin{array}{l}\text { 8. I feel uncomfortable or embarrassed in } \\
\text { exercise clothes during PE classes. }\end{array}$ & 1.58 & 3.08 & $<.0005$ \\
\hline $\begin{array}{l}\text { 9. I see long sessions of exercise during } \\
\text { PE classes as a punishment. }\end{array}$ & 1.53 & 2.50 & $<.0005$ \\
\hline
\end{tabular}

Changes in the amount of activity undertaken in a selection of scenarios during PE classes, at break time and after school, before and after the intervention, were analysed for each group separately. The scale of measurement for each of the scenarios is as follows (Table 4):

- Q10: Students were asked to indicate how often they did each of nine physical activities (sports) during PE classes. A total activity score during PE classes was calculated by summing the responses across the nine sporting activities. The values of this score range from 0 (never do any activity) to 27 (does every activity five or more times in five days).

- Q11: The scale measured how often they were very active during PE classes, ranging from 0 (never) to 5 (always/nearly always).

- Q12: The amount of physical activity done in PE classes for a week ranged from 0 (not at all) to 15 (a lot on all five days).

- Q13: The amount of time spent doing vigorous activity in PE classes ranged from 1 (up to 30 min.) to 4 (>60 min.)

- Q14: The total activity score for physical activity at break and after school ranged from 0 (not at all) to 64 (all of the 16 activities performed seven times or more).

- Q16: The level of activity at break-time ranged from 1 (sat down) to 5 (ran and played hard)

The analysis of the changes, pre- to post-intervention, is shown in Table 4. 
Table 4: Assessment of the students' practices regarding physical activity during school

\begin{tabular}{|c|c|c|c|c|c|c|c|c|c|}
\hline \multirow[b]{2}{*}{ Variable } & \multirow[b]{2}{*}{ Time } & \multicolumn{4}{|c|}{ Intervention group $(n=695)$} & \multicolumn{4}{|c|}{ Control group $(n=498)$} \\
\hline & & $\mathbf{M}(\mathbf{m})$ & SD & $\mathbf{Z}$ & p-value & $\mathbf{M}(\mathbf{m})$ & SD & $\mathbf{Z}$ & p-value \\
\hline \multirow{2}{*}{$\begin{array}{l}\text { 10. The amount of } \\
\text { PA across all sports } \\
\text { in PE classes, in the } \\
\text { last five days }\end{array}$} & Pre & $9.15(9)$ & 4.363 & \multirow[t]{2}{*}{-22.277} & \multirow[t]{2}{*}{$<.0005^{*}$} & $9.32(9)$ & 4.380 & \multirow[t]{2}{*}{-0.706} & \multirow[t]{2}{*}{0.480} \\
\hline & Post & $19.18(19)$ & 2.969 & & & $9.13(9)$ & 4.358 & & \\
\hline \multirow{2}{*}{$\begin{array}{l}\text { 11. In the last five } \\
\text { days, during your } \\
\text { PE classes, how } \\
\text { often were you very } \\
\text { active? }\end{array}$} & Pre & $2.97(3)$ & 0.985 & \multirow{2}{*}{-20.074} & \multirow{2}{*}{$<.0005^{*}$} & $3.15(3)$ & 1.061 & \multirow{2}{*}{-3.104} & \multirow{2}{*}{$.002 *$} \\
\hline & Post & $4.38(4)$ & 0.611 & & & $2.89(3)$ & 1.133 & & \\
\hline \multirow{2}{*}{$\begin{array}{l}\text { 12. How much } \\
\text { physical activity } \\
\text { did you do during } \\
\text { PE classes on each } \\
\text { day, last week? }\end{array}$} & Pre & $7.22(7)$ & 3.362 & \multirow{2}{*}{-11.751} & \multirow{2}{*}{$<.0005^{*}$} & $7.95(8)$ & 3.079 & \multirow{2}{*}{-2.520} & \multirow{2}{*}{$0.012 *$} \\
\hline & Post & $10.61(10)$ & 1.705 & & & $7.57(8)$ & 3.007 & & \\
\hline \multirow{2}{*}{$\begin{array}{l}\text { 13. How much time } \\
\text { did you spend } \\
\text { doing vigorous } \\
\text { physical activities } \\
\text { in PE classes, in the } \\
\text { last week? }\end{array}$} & Pre & $2.30(2)$ & 1045 & \multirow{2}{*}{-16.735} & \multirow{2}{*}{$<.0005^{*}$} & $2.18(2)$ & 0914 & \multirow[b]{2}{*}{-0.472} & \multirow[b]{2}{*}{0.637} \\
\hline & Post & $3.29(3)$ & 0.574 & & & $2.16(2)$ & 0.901 & & \\
\hline \multirow{2}{*}{$\begin{array}{l}\text { 14. How many } \\
\text { times did students } \\
\text { do any of the } \\
\text { following activities } \\
\text { in the past seven } \\
\text { days at break or } \\
\text { after school? }\end{array}$} & Pre & $17.25(16)$ & 8.149 & \multirow[b]{2}{*}{-22.413} & \multirow[b]{2}{*}{$<.0005^{*}$} & $17.12(17)$ & 7.979 & \multirow[b]{2}{*}{-0.524} & \multirow[b]{2}{*}{0.600} \\
\hline & Post & $36.92(37)$ & 5.514 & & & $16.84(17)$ & 8.431 & & \\
\hline \multirow{2}{*}{$\begin{array}{l}15 . \text { In the last five } \\
\text { weekdays, what did } \\
\text { you normally do at } \\
\text { lunch/break } \\
\text { (besides eating)? }\end{array}$} & Pre & & & \multirow[t]{2}{*}{-20.727} & \multirow[t]{2}{*}{$<.0005^{*}$} & & & \multirow[t]{2}{*}{-0.253} & \multirow[t]{2}{*}{0.801} \\
\hline & Post & $3.70(4)$ & 0.723 & & & $1.88(1)$ & 1.031 & & \\
\hline
\end{tabular}

*significance $\mathrm{p} \leq 0.005 ; \mathrm{SD}=$ standard deviation; $\mathrm{M}=$ mean; $(\mathrm{m})=$ median.

The results in Table 4, indicate that the intervention group showed a significant increase in physical activity across all scenarios during PE classes, during lunchtime and after school, pre- to post-intervention. For the control group, the only significant changes are seen in the level of activity during PE classes and the amount 
of time they were very active during PE classes. For both of these, the level of activity decreased significantly after the intervention.

Based on an evaluation of the results, the study showed that the school-based physical activity PDT intervention significantly influenced the students' attitudes and practices regarding participation in physical activity. Students also spent more time doing school-based physical activity.

\section{Discussion}

This study aimed to determine the effects of a school-based physical activity PDT intervention programme for teachers on the attitudes and practices of adolescents regarding physical activity in Lagos, Nigeria. The study considered adolescents' attitudes and practices regarding participation in physical activity during PE classes and at lunch or break-time during the school day.

The PDT intervention programme in this study integrated the autonomous support style of teaching into the approach used by teachers to promote physical activity at school (Yew et al., 2013; Hagger et al., 2013). Following the PDT intervention programme attended by teachers in junior secondary schools, there was an evident improvement in student attitudes and practices regarding physical activity. This is in keeping with several studies, which found that the key to the successful teaching of PE in school is the use of interpersonal teaching methods, and exploring the choices of students as autonomous, supportive teaching methodologies (Graber, 2001; Graham, 2008). In a study conducted by Tessier et al. (2013), similar interpersonal styles improved students' physical activity levels. This finding is consistent with a previous study finding by Draper et al. (2010), which showed an improvement in student practices of, and attitudes to, physical activity in PE classes following a PDT intervention. Many studies have identified that teachers' teaching styles contribute to an improvement in students' attitudes and practices regarding participation in higher-intensity physical activity, particularly on days when they had PE classes (Murtagh \& McKee, 2013; Pate et al., 2011; Meyer et al., 2011).

The teacher is, fundamentally, a facilitator of adolescent physical activity at school. Hiew et al. (2015) found that the teaching methodologies used by PE teachers resulted in improved attitudes and practices in PE classes. In their study the teachers made a deliberate effort to motivate students during PE class, using the new methods learned in their intervention, and this resulted in their students' positive attitudes and practices regarding physical activity (Hiew et al., 2015). In their study, Jenkinson and Benson showed that the involvement of the teachers in the design and implementation of their PDT also contributed to a positive change in the students' attitudes to, and practices in, PE class and they benefitted more from the physical activity (Jenkinson \& Benson, 2010). PE teachers also had an important role in providing students with the skills; knowledge; values; positive perceptions and understanding of the benefits of 
physical activity in order to facilitate long-term engagement in such activities (Hollis et al., 2017). In another study by Baghurst (2012), students' attitudes and practices regarding PE classes were, potentially, believed to be determined by teachers' skills, knowledge and effectiveness in teaching PE. This study highlights the importance of teacher intervention in influencing students' physical activity attitudes and practices.

Cardinal and Cardinal (2001) opined that a PDT programme provides an opportunity for the teachers to acquire skills and knowledge that promote physical activity and fitness. Similarly, the findings of the current PDT programme showed that the skills and knowledge acquired by the teachers during the PDT intervention subsequently influenced the students' practices. Hupinet al. (2019) believed that teachers who engaged in PDT gained skills and knowledge, which subsequently influenced students' attitudes toward PE. Similarly, Coulter (2012) explained that an improvement in physical activity attitudes and practices in the school system is directly linked to teacher capacity and engagement and is thus influenced by PDT interventions for teachers. Coulter (2012) asserts that the skills and knowledge gained by the teachers influence students' attitudes to, and practices in, PE. Adebayo (2015) emphasised in his study that students' attitudes and practices can be influenced by the teachers' teaching skills during PE class. In another paper by Guskey (2003), PDT for teachers was shown to be valuable in improving teachers' knowledge, updating their teaching skills and preparing teachers to address the challenges faced by today's schools.

In the current study, prior to the intervention, some students commented that PE lessons were boring, which contributed to their negative attitude. In line with these findings, Tannehill and Zakrajsek (1993), found that students in high school disliked participating in physical activity due to the dull choices of physical activity by PE teachers. The majority of the students who participated in this study also stated that they were bored by long sessions of exercise during PE classes. They also believed that vigorous physical activity was punishment. Another reason given by the students for their poor attitudes to physical activity was their embarrassment at wearing exercise clothes during PE classes. This was similarly noted in Tannehill and Zakrajsek's (1993) study of high school students who reported that they felt uncomfortable wearing exercise clothes for physical activity. In our study, following the intervention, many students indicated that they enjoyed doing physical activity because PE lessons were considered to be fun. In a study by McKenzie et al. (1994), adolescents indicated a much greater preference for playing games as a form of physical activity; and in a study by Solomon and Carter (1995), high school students were more engaged in PE, based on the 'fun' factor.

After our intervention, an effort was made to gather information on the time spent on physical activity during PE classes and at lunch breaks at school. The participants in our study's intervention group 
showed an improvement in their attitudes and practices regarding physical activity, as well as in increased time spent participating in physical activity, both in PE class and during lunch breaks. Following the intervention, the findings showed an increase of over 45 minutes, from 30 minutes, for the intervention group, as compared to the control group, in the time students spent on vigorous physical activities. Furthermore, the intervention group showed an increase from three to four times per week, compared to the control group who participated once or twice in moderate to vigorous exercise. In a study, by Dobbins et al. (2013), on physical activity interventions for both teachers and students aged 6 and 18 years, the authors found that the physical activity intervention group showed an improvement in the amount of time spent on physical activity - similar to findings in our study. A similar result has been reported in a study on school PE interventions and programmes in midwestern United States primary schools, with an increase of $8 \%$ in the time students spent participating in physical activity daily (Trost et al., 2008).

\section{Conclusion}

In conclusion, teachers who have been trained in the PDT intervention programme will have the capability to effectively teach PE to promote physical activity and healthier lifestyles among adolescents in junior secondary schools in Nigeria. Teachers need regular training on physical activity promotion during PE classes through future, ongoing PDT. Furthermore, the PDT provides opportunities to develop good practices and improved attitudes in the area of physical activity.

The study was limited, as a purposive sample was used to access participants in Nigerian schools, resulting in a non-probability sample. Another limitation was the lack of parental engagement prior to developing the intervention. This would have provided the authors with a deeper understanding of the students' home environments, as well as other possible barriers to participating in physical activity. Studies assert that parental support influences students' attitudes and practices regarding physical activity (Kahar et al., 2018; Fuemmeler et al., 2011). Furthermore, research has shown that parents' involvement in students' physical activity may be effective in improving students' attitudes and practices regarding participation in physical activity (Dunton et al., 2012). Given this situation, Ha et al. (2019) found that involving parents in the physical activity intervention for school children may be beneficial in encouraging positive student attitudes and practices regarding physical activity. This needs to be explored further in our study context. The authors believe that future PDT programmes in Nigerian schools should also include consultation with teachers and school authorities to enhance the development of PDT programmes.

\section{Author contribution}

- Olalekan Remigious Osifeko was the principal researcher and was responsible for data collection, conceptualisation, and drafting of the article. 
- Rowena Naidoo \& Verusia Chetty were the project supervisors and they provided conceptual input into the research methodology and critical input throughout the writing process.

\section{Acknowledgements}

The study was supported by a grant from the College of Health Science, University of KwaZulu-Natal, Durban. South Africa. The authors would like to thank Dr. Gill Hendry for her technical support, and the PE teachers for their participation in the study.

\section{References}

Adebayo, F. A. (2015). Time management and students' academic performance in higher institutions, Nigeria a case study of Ekiti state. International Research in Education, 3(2), 1-12.

Adeniyi, A. F., Okafor, N. C., \& Adeniyi, C. Y. (2011). Depression and physical activity in a sample of Nigerian adolescents: levels, relationships and predictors. Child and adolescent psychiatry and mental health, 5(1), 16.

Adewale, A. F., Odukoya, O. O., Oyeyemi, A. L., Adedoyin, R. A., Ojo, O. S., Metseagharun, E., \& Akinroye, K. K. (2016). Results from Nigeria's 2016 report card on physical activity for children and youth. Journal of physical activity and health, 13(s2), S231-S236.

Akinroye, K. K., Oyeyemi, A. L., Odukoya, O. O., Adeniyi, A. F., Adedoyin, R. A., Ojo, O. S., \& Awotidebe, T. O. (2014). Results from Nigeria's 2013 report card on physical activity for children and youth. Journal of Physical Activity and Health, 11(s1), S88-S92.

Ajoku, L. I. (2013). Professional development of teachers, action planning and utilizing 21 st century skills in Nigerian schools. Journal of Education and Practice, 4(15), 15-20.

Anderson, S. E., Must, A., Phillips, S. M., Curtin, C., Maslin, M., Lividini, K., \& Bandini, L. G. (2014). Comparison of sedentary behaviors between children with autism spectrum disorders and typically developing children. Autism, 18(4), 376-384.

Arbeit, M. L., Johnson, C. C., Mott, D. S., Harsha, D. W., Nicklas, T. A., Webber, L. S. \&

Berenson, G. S. (1992). The Heart Smart cardiovascular school health promotion: behaviour correlates of risk factor change. Preventive Medicine, 21(1), 18-32.

Aubert, S., Barnes, J. D., Abdeta, C., Abi Nader, P., Adeniyi, A. F., Aguilar-Farias, N., \& Tremblay, M. S. (2018). Global matrix 3.0 physical activity report card grades for children and youth: results and analysis from 49 countries. Journal of physical activity and health, 15(s2), S251-S273. 
The Effects of a School-Based Physical Activity Teacher Intervention on the Physical Activity Attitudes and Practices of Adolescent Students in Lagos, Nigeria

Belton, S., \& Mac Donncha, C. (2010). Reliability and validity of a new physical activity self-report measure for younger children. Measurement in physical education and exercise science, 14(1), 1528.

Biddle, S. J., Garcia, E. B., Pedisic, Z., Bennie, J., Vergeer, I., \& Wiesner, G. (2017). Screen time, other sedentary behaviours, and obesity risk in adults: a review of reviews. Current obesity reports, $6(2)$, 134-147.

Cardinal, B. J. \& Cardinal, M. K. (2001). Role modelling in HPERD: Do attitudes match behaviour? Journal of Physical Education, Recreation \& Dance, 72(4), 34-39.

Cheon, S. H., \& Reeve, J. (2015). A classroom-based intervention to help teachers decrease students' amotivation. Contemporary educational psychology, 40, 99-111.

Centers for Disease Control Prevention [CDC]. (2010). The association between schools based physical activity, including physical education, and academic performance, Atlanta, GA: US Department of Health and Human Service sates by sex and cross-sectional age. Medicine and Science in Sports and Exercise, 32, 160-169.

Commonwealth Department of Health \& Family Service (2013). Developing an active Australia: A framework for action for physical and health. Sydney: Department of Education, Science and Training, Common Wealth of Australia.

Community Guide on Physical Activity for preventive services. Promoting physical activity. (2012, 2013 \& 2018) Available at http://www.thecommunityguide.org/pa/index.html. Retrieved on 24/042018.

Coulter, M. (2012). Teaching outdoor and adventure activities: describing, analysing an understanding a primary school physical education professional development programme. Dublin City University.

Creswell, J. W. (2014). A concise introduction to mixed methods research. SAGE publications. Washington DC.

Deirdre, H., (2016). Moving in School: Physical Activity Promotion in the Primary School Setting: A thesis submitted for the award of Doctor of Philosophy (PhD). Department of Arts Education and Physical Education, Mary Immaculate College, University of Limerick, Limerick, Ireland.

Dobbins, M., Husson, H., DeCorby, K., \& LaRocca, R. L. (2013). School-based physical activity programs for promoting physical activity and fitness in children and adolescents aged 6 to 18. Cochrane database of systematic reviews, (2). 
Dunton, G. F., Intille, S. S., Wolch, J., \& Pentz, M. A. (2012). Children's perceptions of physical activity environments captured through ecological momentary assessment: a validation study. Preventive medicine, 55(2), 119-121.

Draper, C., de Villiers, A., Lambert, E., Fourie, J., Hill, J., Dalais, L., Steyn, N. (2010). Healthkick: a nutrition and physical activity intervention for primary schools in low-income settings. BMC Public Health, 10(398), 1-12.

Fuemmeler, B. F., Anderson, C. B., \& Mâsse, L. C. (2011). Parent-child relationship of directly measured physical activity. International Journal of Behavioral Nutrition and Physical Activity, 8(1), 1-9.

Guskey, T. R. (2003). Analyzing lists of the characteristics of effective professional development to promote visionary leadership. NASSP bulletin, 87(637), 4-20.

Graber, J. A., Nichols, T. R., \& Brooks-Gunn, J. (2010). Putting pubertal timing in developmental context: Implications for prevention. Developmental Psychobiology: The Journal of the International Society for Developmental Psychobiology, 52(3), 254-262.

Ha, A. S., Ng, J. Y., Lonsdale, C., Lubans, D. R., \&Ng, F. F. (2019). Promoting physical activity in children through family-based intervention: Protocol of the "Active 1+ FUN" randomized controlled trial. BMC Public Health, 19(1), 1-12.

Hagger, M. S., Jackson, B., Whipp, P. R., Chua, K. P., \& Dimmock, J. A. (2013). Students' tripartite efficacy beliefs in high school physical education: Within-and cross-domain relations with motivational processes and leisure-time physical activity. Journal of Sport and Exercise Psychology, 35(1), 72-84.

Hagger, M. S. (2019). Habit and physical activity: Theoretical advances, practical implications, and agenda for future research. Psychology of Sport and Exercise, 42, 118-129.

Hallal, P. C., Andersen, L. B., Bull, F. C., Guthold, R., Haskell, W., Ekelund, U. \& Lancet Physical Activity Series Working Group. (2012). Global physical activity levels: surveillance progress, pitfalls, and prospects. The lancet, 380(9838), 247-257.

Hiew, C., Chin, Y., Chan, Y., \& Mohd, N. M. (2015). Development and Validation of Knowledge, Attitude and Practice on Healthy Lifestyle Questionnaire (KAP-HLQ) for Malaysian Adolescents. Journal of Nutrition and Health Sciences, 2(4), 1-11.

Hollis, J. L., Sutherland, R., Williams, A. J., Campbell, E., Nathan, N., Wolfenden, L., \& Wiggers, J. (2017). A systematic review and meta-analysis of moderate-to-vigorous physical activity levels in 
The Effects of a School-Based Physical Activity Teacher Intervention on the Physical Activity Attitudes and Practices of Adolescent Students in Lagos, Nigeria

secondary school physical education lessons. International Journal of Behavioral Nutrition and Physical Activity, 14(1), 52.

Hupin, D., Raffin, J., Barth, N., Berger, M., Garet, M., Stampone, K., \& Roche, F. (2019). Even a previous light-active physical activity at work still reduces late myocardial infarction and stroke in retired adults aged $>65$ years by $32 \%$ : the PROOF cohort study. Frontiers in public health, 7, 51.

James, B, D., \& Collier, D. (2011). Increasing the value of physical education: The role of assessment. Journal of Physical Education, Recreation \& Dance, 82(7), 38-41.

Jenkinson, K. A., \& Benson, A. C. (2010). Barriers to Providing Physical Education and Physical Activity in Victorian State Secondary Schools. Australian Journal of Teacher Education, 35(8).

Kahar, A., Gröpel, P., Chen, K., \& Beckmann, J. (2018). Does knowledge of physical activity recommendations increase physical activity among Chinese college students? Empirical investigations based on the transtheoretical model. Journal of sport and health science, 7(1), 7782.

La Torre, G., Mannocci, A., Saulle, R., Sinopoli, A., d'Egidio, V., Sestili, C., \& Masala, D. (2017). Improving knowledge and behaviors on diet and physical activity in children: results of a pilot randomized field trial. Ann Ig, 29(6), 584-594.

Lonsdale, C., Sanders, T., Cohen, K. E., Parker, P., Noetel, M., Hartwig, T., \& Moodie, M. (2016). Scalingup an efficacious school-based physical activity intervention: study protocol for the 'Internet-based Professional Learning to help teachers support Activity in Youth'(iPLAY) cluster randomized controlled trial and scale-up implementation evaluation. BMC public health, 16(1), 873.

Martin, R., \& Murtagh, E. M. (2015). Preliminary findings of Active Classrooms: An intervention to increase physical activity levels of primary school children during class time. Teaching and Teacher Education, 52, 113-127.

Meyer, U., Romann, M., Zahner, L., Schindler, C., Puder, J. J., Kraenzlin, M., \&Kriemler, S. (2011). Effect of a general school-based physical activity intervention on bone mineral content and density: a cluster-randomized controlled trial. Bone, 48(4), 792-797.

Mojisola, O. M., \& Oladimeji, O. (2017). Effects of a multi-level intervention on the pattern of physical activity among in-school adolescents in Oyo state Nigeria: a cluster randomised trial. BMC public health, 17(1), 833 . 
McKenzie, T. L., Alcaraz, J. E., \& Sallis, J. F. (1994). Assessing children's liking for activity units in an elementary school physical education curriculum. Journal of teaching in physical education, 13(3), 206-215.

Murtagh, E., Mulvihill, M., \& Markey, O. (2013). Bizzy Break! The effect of a classroom-based activity break on in-school physical activity levels of primary school children. Pediatric exercise science, 25(2), 300-307.

Ntoumanis, N., Thørgersen-Ntoumani, C., Quested, E., \& Chatzisarantis, N. (2018). Theoretical approaches to physical activity promotion. In Oxford Research Encyclopedia of Psychology.

Pate, R. R., O'Neill, J. R., \& McIver, K. L. (2011). Physical activity and health: Does physical education matter? Quest, 63(1), 19-35.

Physical Activity Guidelines Advisory Committee Report, (2008). Physical Activity Guidelines Advisory Committee Report. Washington, DC: US Department of Health and Human Services; Online retrieved 14/03/2018.

Singh, A., Uijtdewilligen, L., Twisk, J. W., Van Mechelen, W., \& Chinapaw, M. J. (2012). Physical activity and performance at school: a systematic review of the literature including a methodological quality assessment. Archives of pediatrics \& adolescent medicine, 166(1), 49-55.

Solmon, M.A., \& Carter, J.A. (1995). Kindergarten and first -grade students ${ }^{\text {ee }}$ perceptions of physical education in one teacher"s class. The Elementary School Journal, 95(4), 355-365.

Tannehill, D., \& Zakrajsek, D. (1993). Student attitudes towards physical education: A multicultural study. Journal of Teaching in Physical Education, 13(1), 78-84.

Tessier, S., Bonsergent, E., Agrinier, N., Thilly, N., Legrand, K., Lecomte, E., \& PRALIMAP Trial Group. (2013). Overweight and obesity prevention for adolescents: a cluster randomized controlled trial in a school setting. American journal of preventive medicine, 44(1), 30-39.

Trost, S. G., Rosenkranz, R. R., \& Dzewaltowski, D. (2008). Physical activity levels among children attending after-school programs. Medicine \& Science in Sports \& Exercise, 40(4), 622-629.

World Health Organisation. 2013. Global action plan for the prevention and control of non-communicable diseases. Geneva: WHO Press.

Yew, H. M., Whipp, P., Dimmock, J., \& Jackson, B. (2013). The effects of choice on autonomous motivation, perceived autonomy support, and physical activity levels in high school physical education. Journal of teaching in physical education, 32(2), 131-148. 